\title{
Psychiatric Expertise in Benin Penal Justice Context: What Do They Reveal?
}

\author{
Francis Tognon ${ }^{1}$, Cedric Bigot ${ }^{2}$, Yves Amonles², Feldia Adéossi² \\ ${ }^{1}$ Unit of Psychiatry, Faculté de Médecine, Parakou, Benin \\ ${ }^{2}$ Department of Medicine, Facultés de Sciences de la Santé, Cotonou, Benin \\ Email: ${ }^{\star}$ fgaspar@ysu.am
}

How to cite this paper: Tognon, F., Bigot, C., Amonles, Y. and Adéossi, F. (2020) Psychiatric Expertise in Benin Penal Justice Context: What Do They Reveal? Open Journal of Psychiatry, 10, 1-8.

https://doi.org/10.4236/ojpsych.2020.101001

Received: November 15, 2019

Accepted: December 17, 2019

Published: December 20, 2019

Copyright (c) 2020 by author(s) and Scientific Research Publishing Inc. This work is licensed under the Creative Commons Attribution International License (CC BY 4.0).

http://creativecommons.org/licenses/by/4.0/

\section{(c) (i) Open Access}

\begin{abstract}
In this study, the authors describe the profile of people seen in criminal psychiatric expertise in northern Benin and their results. It covered the 138 psychiatric assessments carried out as part of criminal proceedings in the years 2017 and 2018. Expertises were on men in $94.9 \%$ of the cases. They were over 30 years old in $66.2 \%$ of cases. They were prosecuted for blood crimes in $89.5 \%$ of cases. The defendants were in detention at the time of the expert in $87.5 \%$ of cases. Psychiatric experts diagnosed a psychiatric disorder in $22.8 \%$ of cases. There was a relationship between the identified psychiatric disorder and the offense that motivated the charge in $25.8 \%$ of the mental disorder cases. It was exclusively cases of psychotic disorders. There was an abolition of discernment in $3.8 \%$ of the accused.
\end{abstract}

\section{Keywords}

Psychiatric Expertise, Criminal Responsibility, Psychoses, Forensic Psychiatry, Dangerousness

\section{Introduction}

In judicial practice, a magistrate confronted with a problematic situation has latitude in requesting any person of his choice to supplement his observations, by either consultation or offering input, on a criminal incident that requires expert knowledge [1]. Article 173 of the Code of Criminal Justice of Benin suggests that "any court may order expert appraisal in the case that a question of a technical nature arises" [2].

In the penal context, psychiatric expertise is highly sought after. Unlike thanatological, anatomopathological or toxicological expertise, it is very inexpensive. Psychiatric expertise may relate to the victim of the offence or to the person 
charged with the offence. The criminal responsibility of the accused is described by the Penal Code, which states in article 64 that "there is no crime or offence when the defendant was in a state of insanity at the time of the action or when he was compelled by a power he could not resist" [3]. The notion of dementia refers here to psychic or neuropsychic disorders that may justify criminal irresponsibility. It is accepted in law that a person who, at the time of the crime, suffers from a psychic disorder or is in a psychotic state and has lost his judgement or control of his acts could not be held responsible for his acts [4]. As part of the criminal proceedings, the judge asks a doctor to educate him on the subject. This doctor, after examining the accused, will enlighten the magistrate about the existence of a psychiatric disorder. If necessary, the doctor will have to decide on the existence of a relationship between the psychiatric disorder identified and the offence committed. He will also have to decide the impact of the disorder on the accused's capacity for discernment. The doctor can additionally assess the danger of the accused to themselves and others and determine possible care measures.

This study examined the beneficiaries of this type of expertise, the circumstances in which such testimony is carried out and its results.

\section{Methods}

This study is a cross-sectional, descriptive, retrospective and mono-centric. It concerned all the criminal psychiatric expert appraisals carried out in the department of psychiatry of the Departmental and University Hospital Centre of Borgou in Parakou. The reports on the expert appraisals carried out during the years 2017 and 2018 and the related requisitions have been collected. The sample was composed with all the criminals prosecuted for a criminal offence which had been examined in the department at the request of a judge. To be included in the study, the person had to be over 18 years old, and the mission requested by the judge had to be related to the state of mental health of the subject. Civilian appraisals were not considered. A scorecard developed as part of this study was used to analyse the reports. We distinguished three categories of variables: Sociodemographic variables, those related to the medico-legal context and those related to the conclusions of the experts. To guarantee judicial secrecy, the investigators did not have access to information that could have made it possible to identify the person about whom the expertise was provided. The data was encoded and then analysed with SPSS v25 software. The variables were described in terms of frequency, mean and standard deviation.

\section{Results}

\subsection{Sociodemographic Characteristics}

A total of 138 medico-psychiatric assessments were included in this study. Table 1 presents the distribution of subjects by sociodemographic characteristics. Male subjects accounted for $94.9 \%(n=131)$ of all people surveyed. The average age at 
Table 1. Sociodemographics characteristics.

\begin{tabular}{|c|c|c|}
\hline & $\mathrm{n}$ & $\%$ \\
\hline \multicolumn{3}{|l|}{ Gender } \\
\hline Male & 129 & 94.85 \\
\hline Female & 7 & 5.15 \\
\hline \multicolumn{3}{|l|}{ Age (years) } \\
\hline [14 - 19] & 14 & 10.29 \\
\hline [20 - 29] & 32 & 23.53 \\
\hline$[30-39]$ & 39 & 28.68 \\
\hline$[40-49]$ & 31 & 22.79 \\
\hline$[50-59]$ & 14 & 10.29 \\
\hline$[60-70]$ & 6 & 4.41 \\
\hline \multicolumn{3}{|l|}{ Type of employment } \\
\hline Agricultural production & 59 & 43.38 \\
\hline Cattle breeding & 39 & 28.68 \\
\hline Employee & 10 & 7.35 \\
\hline Trader & 3 & 2.21 \\
\hline Artisan & 16 & 11.76 \\
\hline Unemployed & 9 & 6.62 \\
\hline \multicolumn{3}{|l|}{ Religion } \\
\hline Islam & 99 & 72.79 \\
\hline Chritianity & 29 & 21.32 \\
\hline Endodenous & 3 & 2.21 \\
\hline No religion & 5 & 3.68 \\
\hline \multicolumn{3}{|l|}{ Marital status } \\
\hline Married & 98 & 72.06 \\
\hline Single & 35 & 25.74 \\
\hline Divorced & 3 & 2.21 \\
\hline \multicolumn{3}{|l|}{ Origine } \\
\hline Beninese & 125 & 91.90 \\
\hline Non Beninese & 11 & 8.10 \\
\hline \multicolumn{3}{|l|}{ Level of schooling } \\
\hline Unschooled & 80 & 58.82 \\
\hline Primairy & 27 & 19.85 \\
\hline Secondary & 18 & 13.24 \\
\hline University & 11 & 8.09 \\
\hline \multicolumn{3}{|l|}{ Socioeconomic level } \\
\hline Low & 81 & 59.6 \\
\hline Average & 49 & 39.0 \\
\hline Hight & 5 & 3.7 \\
\hline
\end{tabular}


the time of the surveys was approximately 36 years (mean $=35.8$ years, standard deviation 13 years). The extreme ages were 14 and 70 years old. The most represented age group was [30 - 39] years. Subjects reported being married in $72.6 \%$ of cases $(\mathrm{n}=98)$. Among them, 42 subjects had more than one wife $(42.9 \%)$. Islam was the most widely practised religion $(72.9 \%)$. A proportion of $21.3 \%$ of the sample had attained education beyond primary school $(n=29)$.

\subsection{Medico-Legal Context}

All expert appraisals were related to persons prosecuted for incidents qualified as crimes. Table 2 shows the distribution of subjects according to the charges raised against them. Of the 13 sexual offences, there were nine (69.2\%) prosecutions for minor rape. Deadly blows (36.0\%) and assassinations (26.5\%) were the primary reasons for prosecuting cases of homicides.

The accused persons recognized the crimes with which they were accused in $69.9 \%$ of the cases $(\mathrm{n}=95)$.

In blood crimes $(\mathrm{N}=102)$, information on alleged victims was available in $82.3 \%$ of cases $(n=84)$. There were 36 female victims $(42.9 \%)$. The victim was known to the accused in $46.4 \%$ of the cases $(n=39)$. The victim was related to the prosecuted individual in 13 cases. Three $(2.2 \%)$ of the reported blood crimes were related to the context of domestic violence.

The requests for expert appraisals came from courts of appeal (86.8\%) and courts of first jurisdiction (13.2\%). The most common applicants were the attorney-generals, who issued $79.4 \%$ of psychiatric and psychiatric appraisals for this series $(\mathrm{n}=108)$. The defendants in detention at the time of the expert appraisals accounted for $87.5 \%$ of the study population. Only six appraisals were ordered before the end of the first year of detention of the accused.

Table 2. Reason for prosecution.

\begin{tabular}{ccc}
\hline Law offences & $\mathbf{n}$ & $\%$ \\
\hline Sexuel offences & 13 & 9.56 \\
Rape & 1 & 0.74 \\
Sexual touching & & \\
Homicide & 49 & 36.03 \\
Deadly blows & 36 & 26.47 \\
Assassination & 17 & 12.50 \\
murder & & \\
Autres infractions & 8 & 5.88 \\
Steal & 7 & 5.15 \\
Aggravated injuries & 3 & 2.21 \\
quackery & 2 & 1.47 \\
\hline Human organs trafficking &
\end{tabular}




\subsection{Results of the Medical-Psychiatric Examination}

The accused persons reported having a psychiatric history in $2.9 \%$ of cases $(\mathrm{n}=$ 4). Only one of the subjects was able to demonstrate that his pathology (depression) had been medically treated. For the other 3 , the pathology was not identifiable, and the treatment was performed with endogenous means.

Medical history (non-psychiatric) was reported by 26 subjects (19.1\%). These antecedent conditions included forms of arterial hypertension (18 cases), diabetes ( 3 cases), hearing impairment ( 3 cases) and respiratory illness ( 2 cases).

A psychiatric disorder was diagnosed in 31 of the accused (22.8\%). Table 3 shows the distribution of medico-psychological afflictions among the accused. The frequency of psychiatric disorders was 38.5 in the group of those with a low socio-economic level compared to $9.3 \%$ in the rest of the population $(\mathrm{p}=0.001)$.

Psychotic disorders accounted for $29.0 \%$ of psychiatric disorders.

In the psychotic disorders group, there was a relationship between the identified psychiatric disorder and the offence that motivated the charge in $25.8 \%$ of the mental disorder cases. Criminal responsibility was abolished in $3.8 \%$ of the accused and was altered in $2.2 \%$. The cases in which criminal responsibility was abolished or altered exclusively concerned accused persons diagnosed with a psychotic disorder.

Four of the accused were described as having a dangerous character requiring psychiatric detention (2.9\%).

The accused who were considered to be fully responsible accounted for $94.9 \%$ of the total number of subjects. Of the seven accused for whom the expert opinion was in favour of a lack of criminal responsibility, 5 of them, or $71.4 \%$, had spent more than three years in prison before being examined by the expert.

\section{Discussion}

This study examines the profile of persons charged with crimes and subjected to a medical-psychiatric forensic examination; the primary purpose of this work was to ensure that the accused had full discretion at the time of the act.

The study reveals that the defendants submitted for expert appraisal were mostly young adults aged between 20 and 40, male (94.85\%) and married (72.6\%). The vast majority of them did not attend school. These indictees had

Table 3. Distribution of psychiatric disordes.

\begin{tabular}{ccc}
\hline & $\mathrm{n}$ & $\%$ \\
\hline Troubles psychotiques & & \\
Schizophrenia & 5 & 3.7 \\
Psychotic disorder due to drugs & 2 & 1.5 \\
Puerperal psychosis & 1 & 0.7 \\
Neurodegenerative disorder (dementia) & 1 & 0.7 \\
Depressive disorder & 22 & 16.2 \\
\hline
\end{tabular}


characteristics similar to those of the prison population observed in Benin and other countries of sub-Saharan Africa. A study conducted in prisons in southern Benin found that men accounted for $93.9 \%$ of the prison population [5]. In Nigeria, those charged with homicide are men in $93 \%$ of cases [6]. The metaanalysis conducted in 2019 by Lovett et al. revealed that the prison population in sub-Saharan Africa consisted of men in proportions ranging from $93 \%$ to $100 \%$ [7]. The average ages fell primarily in the age group of 31 - 37 years [7]. In our series, the accused are most commonly married (72\%) individuals who did not receive formal education (59\%). Similar observations are also made in Burkina Faso [8], Nigeria [9], and Uganda [10].

In our series, homicides (75\%) and rapes (9.6\%) were the crimes for which medical-psychiatric expertise was most often requested. These crimes are considered violent crimes and are tried during assizes. In Benin's judicial practice, the absence of a psychiatric report in the accused's file is often a reason for referral of the case to a later session. This tendency explains why the majority of the appraisals were requested by magistrates of the court of appeal.

In the prison environment, the prevalence of psychiatric disorders is generally high, among which depressive disorders are the most frequent [11] [12] [13]. In our study, the frequency of depressive disorders seems relatively low (19.8\%) compared to the results of Nanema et al. [8] and those of Osasona et al. [14], who reported prevalences of $33 \%$ and $78 \%$, respectively. The variations in prevalence observed from one study to the next can be explained by choice of assessment tools for disorders but also by the socio-cultural context [15]. In the specific context of our study, the under-representation of depressive disorders can be explained by the lack of relevance of their evocation in the context of the evaluation of criminal irresponsibility during violent crimes. The risk of a depressive subject committing a violent crime is low [16] [17]. Indeed, individuals with depression are more likely to be victims of [18] homicide. As a result, experts tend not to insist on exploring this type of pathology in their reports. Attention is more focused on the psychotic disorders that are most associated with violent crime. In our series, the frequency of psychotic disorders was $5.9 \%$. These disorders were all been diagnosed in people charged with blood crimes. Many authors have stated that there is an increased risk of violence in people with schizophrenia [19] or psychoses. A major mental disorder may be observed in $15 \%$ of murderers, and psychotic disorders multiply the risk of committing an act of violence by 10 in men compared to 8 in women [19]. Homicides perpetrated by people with psychotic disorders account for between $4 \%$ and $10 \%$ of all homicides. The accused often have risk factors such as young age, male sex and low socioeconomic level [20]. In our study, only the low socioeconomic level significantly affects psychiatric disorders. More than the diagnosis of mental illness, the relationship between the illness and the criminal act is what interests the judge. The findings of the expert appraisal strongly impact the answer to the question of criminal responsibility; the more recent the crime is, the better the 
expert will be able to answer this question. At a distance from the facts, it may be difficult to distinguish an individual lying about a mental condition from the one who actually acted under the influence of a psychosis induced by a drugs The two accused in our series for whom such a diagnosis was made benefited from early expert appraisal. The expert can only form a decision based on his findings. Without clinical evidence, he cannot support the abolition or alleviation of the accused's criminal culpability. In cases of belated review, the accused, if found not guilty, is deprived of his right not to be imprisoned or to have his sentence reduced. Improving inmate access to medical and psychiatric care may help to prevent these kinds of unfortunate situations. In Benin practice model, a doctor is required to examine the accused in police custody and determines the necessity of providing psychiatric expertise. But justice does not charge him for the care. Indeed the expert physician can not be the attending physician. Because of that in this study, the results of the therapeutics interventions could not be presented. In fact psychiatric disorders of these people are not often treated. Expertise is the only opportunity for him to meet a psychiatrist. They do not receive any treatment after the consultation. Prison policy in Benin should include psychiatric care to prisoners. It is also necessary to go beyond it. The work to be done upstream is to make psychiatric consultations more accessible to the people and to destroy the existing taboos on mental illness. It is the way to reduce incidence the influence of psychiatric disorders on crime

\section{Conclusion}

Medical-psychiatric expert appraisals that result in a decision in favour of criminal irresponsibility are not frequent. Such appraisals are nonetheless necessary, even indispensable, for the correct administration of justice. Benin's justice system could benefit the utilization of more frequent expert appraisals that take place earlier in the criminal justice process.

\section{Conflicts of Interest}

The authors declare no conflicts of interest regarding the publication of this paper.

\section{References}

[1] Ludes, B. (2016) Forensic Expertise. Ethics, Medicine and Public Health, 2, 87-92. https://doi.org/10.1016/j.jemep.2016.01.008

[2] National Assembly, Republic of Benin (2012) Law No. 2012-15 on the Code of Criminal Procedure in the Republic of Benin.

[3] Bouvenet, G.-J. and Hutin, P. (1877) Annotated Collection of Criminal Law Texts Applicable in French West Africa. Editions of the French Union, Paris.

[4] Galland, D., Jonas, C., Jardri, R., Wilquin, M., Cottencin, O., Thomas, P., et al. (2016) Comparison of the Concept of "Responsibility" in Neuroscience and in French Criminal Law: A Cross-Literature Review for the Psychiatric Forensic Practice. La Presse Médicale, 45, 559-566. https://doi.org/10.1016/j.lpm.2016.03.018

[5] Aguemon, B., Damien, G., Padonou, G., Djossou, E., Kouwakanou, B. and Ayelo, P. 
(2016) Living Conditions and Access to Women's Health Services at the Cotonou Civil Prison. CBRST Papers, (10), 80-96.

[6] Mafullul, Y.M., Ogunlesi, O.A. and Sijuwola, O.A. (2001) Psychiatric Aspects of Criminal Homicide in Nigeria. East African Medical Journal, 78, 35-39.

https://doi.org/10.4314/eamj.v78i1.9110

[7] Lovett, A., Kwon, H.R., Kidia, K., Machando, D., Crooks, M., Fricchione, G., et al. (2019) Mental Health of People in the Justice System in Africa: Systematic Review and Meta-Analysis. International Journal of Mental Health Systems, 13, 31-72. https://doi.org/10.1186/s13033-019-0273-Z

[8] Nanema, D., Goumbril, P., Karfo, K., Ouango, G. and Ouedraogo, A. (2014) Epidemiological and Clinical Aspects of Psychiatric Disorders in Prison in Ouagadougou, Burkina-Fasso. African Annals of Psychiatry, 3, 64-79.

[9] Mafullul, Y.M. (2005) Criminal Homicide in Nigeria: A Socio-Psychiatric Review. Archives of Ibadan Medicine, 4, 9-12. https://doi.org/10.4314/aim.v4i1.34595

[10] Forry, J.B., Ashaba, S. and Rukundo, G.Z. (2019) Mbarara Municipality, Southwestern Uganda: A Cross-Sectional Study. BMC Psychiatry, 19, 178-186. https://doi.org/10.1186/s12888-019-2167-7

[11] Richie, F., Bonner, J., Wittenborn, A., Weinstock, L.M., Zlotnick, C. and Johnson, J. (2019) Social Support and Suicidal Ideation among Prisoners with Major Depressive Disorder. Archives of Suicide Research: Official Journal of the International Academy for Suicide Research, 1-8. https://doi.org/10.1080/13811118.2019.1649773

[12] Baier, A., Fritsch, R., Ignatyev, Y., Priebe, S. and Mundt, A.P. (2016) The Race of Major Depression during Imprisonment-A One Year Cohort Study. Journal of Affective Disorders, 189, 207-213. https://doi.org/10.1016/j.jad.2015.09.003

[13] Tung, T.-H., Hsiao, Y.-Y., Shen, S.-A. and Huang, C. (2019) The Prevalence of Mental Disorders in Taiwanese Prisons: A Nationwide Population-Based Study. Social Psychiatry and Psychiatric Epidemiology, 54, 379-386. https://doi.org/10.1007/s00127-018-1614-y

[14] Osasona, S.O. and Koleoso, O.N. (2015) Prevalence and Correlates of Depression and Anxiety Disorder in a Nigerian Prison. The International Journal of Psychiatry in Medicine, 50, 203-218. https://doi.org/10.1177/0091217415605038

[15] Siddique, J.A. (2016) Age, Marital Status, and Risk of Sexual Victimization: Similarities and Differences across Victim-Offender Relationships. Journal of Interpersonal Violence, 31, 2556-2575. https://doi.org/10.1177/0886260515579507

[16] da Silva, A.T.C. and Menezes, P.R. (2015) Depression and Violent Crime: Is There a Relationship? Evidence-Based Mental Health, 18, 114-114. https://doi.org/10.1136/eb-2015-102104

[17] Furukawa, T.A. (2015) The Relationship between Depression and Violent Crime. The Lancet Psychiatry, 2, 193-194. https://doi.org/10.1016/S2215-0366(15)00046-2

[18] Fazel, S., Wolf, A., Chang, Z., Larsson, H., Goodwin, G.M. and Lichtenstein, P. (2015) Depression and Violence: A Swedish Population Study. The Lancet Psychiatry, 2, 224-232. https://doi.org/10.1016/S2215-0366(14)00128-X

[19] Fazel, S., Gulati, G., Linsell, L., Geddes, J.R. and Grann, M. (2009) Schizophrenia and Violence: Systematic Review and Meta-Analysis. PLoS Medicine, 6, e1000120. https://doi.org/10.1371/journal.pmed.1000120

[20] Richard-Devantoy, S., Bouyer-Richard, A.I., Jollant, F., Mondoloni, A., Voyer, M. and Senon, J.-L. (2013) Homicide, Schizophrenia and Substance Abuse: Dangerous Liaisons? Journal of Epidemiology and Public Health, 61, 339-350. https://doi.org/10.1016/j.respe.2013.01.096 